\title{
GABA Predicts Time Perception
}

\author{
Devin B. Terhune, ${ }^{1}$ Sonia Russo, ${ }^{1}$ Jamie Near, ${ }^{3}$ Charlotte J. Stagg, ${ }^{2}$ and Roi Cohen Kadosh ${ }^{1}$ \\ ${ }^{1}$ Department of Experimental Psychology and ${ }^{2}$ Centre for Functional MRI of the Brain, Nuffield Department of Clinical Neurosciences, John Radcliffe \\ Hospital, University of Oxford, Oxford OX3 9DU, United Kingdom, and ${ }^{3}$ Douglas Mental Health University Institute and Department of Psychiatry, McGill \\ University, Verdun, Québec H4H 1R2, Canada
}

Our perception of time constrains our experience of the world and exerts a pivotal influence over a myriad array of cognitive and motor functions. There is emerging evidence that the perceived duration of subsecond intervals is driven by sensory-specific neural activity in human and nonhuman animals, but the mechanisms underlying individual differences in time perception remain elusive. We tested the hypothesis that elevated visual cortex GABA impairs the coding of particular visual stimuli, resulting in a dampening of visual processing and concomitant positive time-order error (relative underestimation) in the perceived duration of subsecond visual intervals. Participants completed psychophysical tasks measuring visual interval discrimination and temporal reproduction and we measured in vivo resting state GABA in visual cortex using magnetic resonance spectroscopy. Time-order error selectively correlated with GABA concentrations in visual cortex, with elevated GABA associated with a rightward horizontal shift in psychometric functions, reflecting a positive time-order error (relative underestimation). These results demonstrate anatomical, neurochemical, and task specificity and suggest that visual cortex GABA contributes to individual differences in time perception.

\section{Introduction}

There is increasing recognition that the timing of subsecond intervals is subserved by distributed sensory- or context-specific mechanisms (Mauk and Buonomano, 2004; Grondin, 2010; Bueti, 2011). Recent research using electrophysiological recordings from sensory-processing-relevant brain regions in macaques strongly suggests that stimulus-specific neuronal activity contributes to subsecond interval timing. Sadeghi et al. (2011) found that neuronal activity in $\mathrm{V} 5 / \mathrm{MT}$ in macaques was greater for oddball (novel) stimuli presented at the end of a sequence of homogeneous motion stimuli (standards). Human volunteers perceive oddballs to be longer in duration than standard stimuli, suggesting that the perceived dilation of a stimulus is a direct consequence of local stimulus-specific neuronal activity (Eagleman and Pariyadath, 2009). A second study (Mayo and Sommer, 2013) similarly found that the strength of the neuronal response in frontal eye field to visual comparison intervals predicted whether macaques misperceived the intervals relative to standard intervals. Relative to correct responses, overestimation was asso-

Received Sept. 17, 2013; revised Jan. 26, 2014; accepted Feb. 18, 2014.

Author contributions: D.B.T., S.R., and R.C.K. designed research; D.B.T. and S.R. performed research; D.B.T., J.N., and C.J.S. contributed unpublished reagents/analytic tools; D.B.T. analyzed data; D.B.T. and R.C.K. wrote the paper.

This work was supported by the Cogito Foundation (to D.B.T.). D.B.T. is also supported by a Marie SkłodowskaCurie Intra-European Fellowship within the 7th European Community Framework Programme. R.C.K. is supported by the Wellcome Trust (Grant WT88378). We thank T.R. Makin for noting, Ralph Mekle for development of the MRS-SPECIAL sequence and Priya Kochuparampil for research assistance.

The authors declare no competing financial interests.

This article is freely available online through the J Neurosci Author Open Choice option.

Correspondence should be addressed to Devin Blair Terhune, Department of Experimental Psychology, University of Oxford, South Parks Road, 0xford OX1 3UD, UK. E-mail: devin.terhune@psy.ox.ac.uk.

DOI:10.1523/JNEUROSCI.3972-13.2014

Copyright (c) 2014 Terhune et al.

This is an Open Access article distributed under the terms of the Creative Commons Attribution License (http://creativecommons.org/licenses/by/3.0), which permits unrestricted use, distribution and reproduction in any medium provided that the original work is properly attributed. ciated with a larger neuronal response, whereas underestimation was associated with a smaller neuronal response. These results suggest that the magnitude of the stimulus-specific neuronal response determines the perceived duration of the stimulus. Accordingly, interindividual heterogeneity in the perceived duration of subsecond intervals (Wiener et al., 2013) may arise from variability in endogenous constraints on the neuronal response to sensory stimuli.

Multiple studies demonstrate that GABA dampens visual processing and its neural substrates, thereby implicating GABA as a potential mediating factor in the perceived duration of visual intervals. $\mathrm{GABA}_{\mathrm{A}}$ agonists have been shown to impair visual discrimination (Giersch and Herzog, 2004), reduce visual awareness (van Loon et al., 2012), and attenuate the neurophysiological response ( $\mathrm{P} 3$ event-related brain potential component) to visual oddball stimuli (Watson et al., 2009), which are typically perceived to be dilated (Eagleman and Pariyadath, 2009).

On the basis of these findings, we hypothesized that elevated GABA in visual cortex suppresses the firing of excitatory neurons that code for particular visual stimuli or visual intervals, thereby deteriorating visual processing. Perceived duration is closely tied to the allocation of processing resources to a stimulus (Buhusi and Meck, 2009), so a GABA-mediated deterioration of stimulus processing and concomitant reduction in visual awareness should produce a perceived contraction of comparison stimuli relative to standard stimuli (Terao et al., 2008; Eagleman and Pariyadath, 2009; Mayo and Sommer, 2013). We used a duration discrimination task in which participants encoded the intervals of a series of homogeneous standards and then judged comparison intervals of varying duration relative to the standards. We tested the prediction that resting state GABA levels in visual cortex, as measured by magnetic resonance spectroscopy (MRS; Stagg et al., 2011a; 

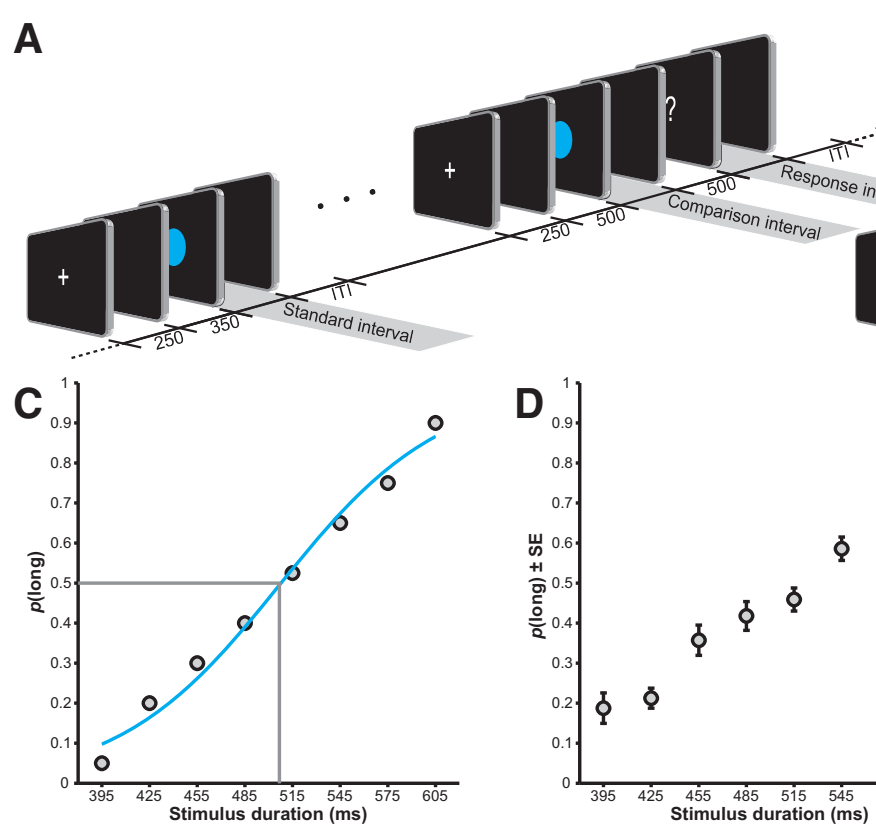

B
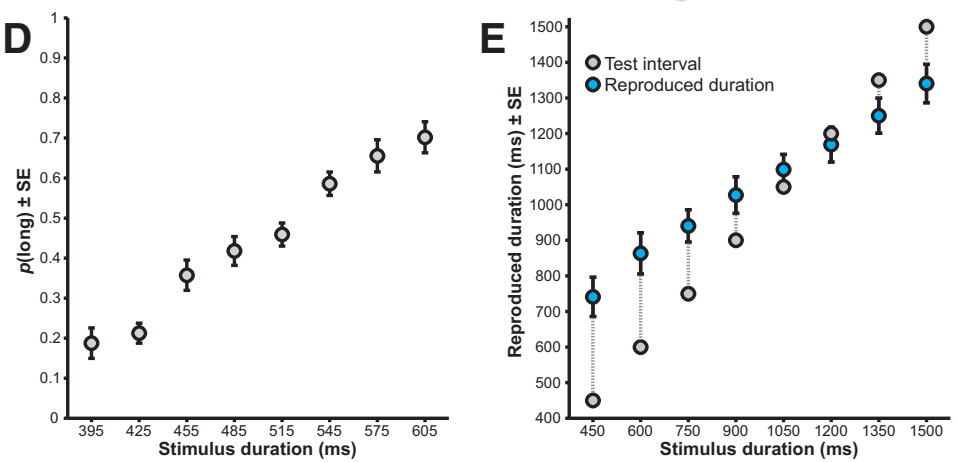

Figure 1. Task structures and data. Shown are schematic diagrams of duration discrimination $(\boldsymbol{A})$ and duration reproduction $(\boldsymbol{B})$ task structures. C, Example fit (blue) of a randomly selected participant's data (gray circles) in the duration discrimination task; the PSE is identified by the intersection of the logistic function and the 0.5 threshold (gray line). $\boldsymbol{D}, M \pm S E p$ (long) responses (across participants) in the duration discrimination task. E, $M \pm$ SE reproduced durations (blue) and test intervals (gray; across participants) in the duration reproduction task; broken lines reflect reproduction deviation.

Puts and Edden, 2012), would be associated with relative underestimation of subsecond visual intervals (positive timeorder error; Hellström, 1985, 2003).

\section{Materials and Methods}

Participants. Fifteen right-handed (Chapman and Chapman, 1987) healthy participants ( 12 female, median age $23.3 \pm 5.1$ years) with normal or corrected-to-normal visual acuity participated in the study. None had a history of psychiatric or neurological illness nor did any display contraindications for magnetic resonance imaging (MRI). Participants provided informed consent to take part in accordance with the approval of a local ethics committee. To control for the possible confounding effect of menstrual cycle on GABA (Epperson et al., 2002), female participants were classified as being in the follicular phase (first $14 \mathrm{~d}$ of cycle; $n=8$ ), as being in the luteal phase (last $14 \mathrm{~d}$ of cycle, $n=3$ ), or as having no phase because of medication $(n=1)$.

Duration discrimination. In this task, participants were first instructed to estimate and memorize the duration of a standard interval (blue circle) that was presented repeatedly (Fig. $1 A$ ). Subsequently, they were presented with a comparison interval (blue circle) and a response screen prompting them to judge whether the comparison was shorter or longer than the standard by depressing one of two keys with their right index or right middle finger, respectively. The standard interval was fixed at 500 $\mathrm{ms}$, whereas comparison intervals varied from 395 to $605 \mathrm{~ms}$ at $30 \mathrm{~ms}$ increments (395, 425, 455, 485, 515, 545, 575, or $605 \mathrm{~ms})$.

Duration reproduction. In this task (Fig. $1 B$ ), participants were instructed to estimate and memorize the duration of an empty test interval (blank screen between a white fixation cross and a blue circle). This interval varied from 450 to $1500 \mathrm{~ms}$ in increments of $150 \mathrm{~ms}(450,600$, $750,900,1050,1200,1350$, and $1500 \mathrm{~ms}$ ). Participants were subsequently presented with a blue fixation cross, which prompted them to hold the response key with their right index finger for the same duration as the test interval. Upon depressing the response key, a blank screen appeared to mimic the test interval. Upon release of the response key, a white circle was presented, completing the interval.

Procedure. Participants completed the (counterbalanced) tasks and MR session on separate days. Participants completed the two tasks at a distance of $70 \mathrm{~cm}$ with fixation and interval stimuli subtending visual angles of $1^{\circ}$ and $2.5^{\circ}$, respectively. Trials in both tasks were separated by a jittered intertrial interval (ITI) ranging from 500 to $700 \mathrm{~ms}$ in increments of $50 \mathrm{~ms}$. In the duration discrimination task, participants completed one practice block of five standards and 16 trials and four blocks of 10 standards and 80 trials. In the duration reproduction task, participants completed one practice block of 16 trials and four blocks of 80 trials. Participants responded using a Cedrus response pad. Stimulus presentation was implemented with E-Prime version 2.0 (Psychology Software Tools).

MRI data acquisition. All participants were scanned on a 3T Siemens scanner with a body coil transmitter and a 32-channel receiver head array. We first acquired a high-resolution T1-weighted scan using a magnetization-prepared rapid gradient echo (MPRAGE) sequence (Stagg et al., 2011c). Short-TE MRS data were next acquired in two localized voxels measuring $2 \times 2 \times 2 \mathrm{~cm}$ in primary visual cortex and in the hand knob in the left hemisphere, known to represent the hand area of primary motor cortex (Stagg et al., 2011c; Fig. 2) under eyes-open conditions in counterbalanced order. Shimming was performed using the vendor-provided automated shim tool. Short-TE MR spectra were acquired with the spin-echo full-intensity acquired localized (SPECIAL) sequence (2048 points, spectral width $=2000 \mathrm{~Hz}, \mathrm{TR} / \mathrm{TE}=4000 / 8.5 \mathrm{~ms}$, 128 averages; Mekle et al., 2009). Outer volume suppression was applied before each scan to saturate spins on all six sides of the voxel of interest, and variable power RF pulses with optimized relaxation delays (VAPOR) water suppression was used (Tkác et al., 2001). Last, eight averages of water-unsuppressed data were acquired with the same localization scheme. This method was used to compute concentrations of GABA, glutamate, and creatine; note that other neurotransmitters implicated in time perception, such as dopamine (Coull et al., 2011) and serotonin (Sysoeva et al., 2010), cannot be measured with proton MRS because of their low concentrations in vivo.

Behavioral data analysis. Duration discrimination data were modeled using the Palamedes toolbox (Prins and Kingdom, 2009) for MATLAB (The MathWorks) and duration reproduction data were analyzed using customized routines in MATLAB. In the former, for each participant, the probabilities of a long response [ $p$ (long)] across comparison intervals were fitted with a logistic function (Fig. $1 C$ ) defined by four parameters: threshold $\alpha$, slope $\beta$, guess rate $\gamma$, and lapse rate $\lambda$. The threshold and slope were set as free parameters that were estimated using maximum likelihood estimation, whereas guess and lapse rates were fixed at 0 and 


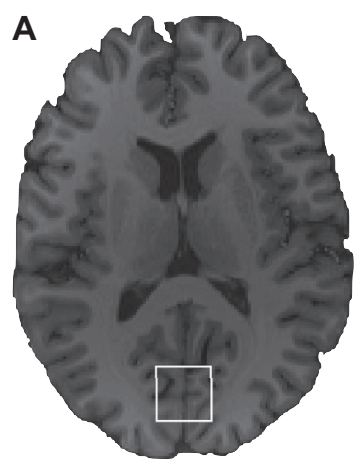

B
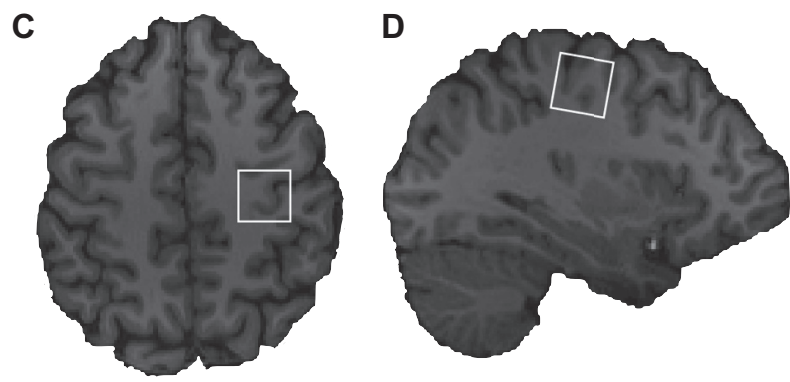

Figure 2. MRS voxel locations from a randomly selected participant. Shown are visual cortex axial $(\boldsymbol{A})$ and sagittal $(\boldsymbol{B})$ views and motor cortex axial $(\boldsymbol{C})$ and sagittal $(\boldsymbol{D})$ views.

0.1 , respectively. Model fit was acceptable for all participants (pDevs $>$ 0.2; Kingdom and Prins, 2010). The location of the psychometric function at $p$ (long) $=0.5$ was taken as the point of subjective equality (PSE), the duration of the comparison interval that is perceived as equivalent to the standard interval (Fig. 1C,D). PSE values were interpreted as reflecting time-order error in the task: values $>500$ and $<500$ reflect relative underestimation and overestimation, respectively, of the comparison intervals. Response precision was computed with the Weber fraction (WF), which is the difference limen $[(t(p$ (long $)=0.75)-t(p$ (long $)=$ $0.25)$ )/2] divided by the PSE.

In the duration reproduction task, we calculated the deviation of response durations from the corresponding test interval (Fig. 1E). Mean deviation across intervals $\left(M_{\mathrm{dev}}\right)$ was used as a measure of temporal reproduction (larger values reflect underreproduction) as a control for time-order error in the duration discrimination task.

$M R S$ postprocessing and analysis. Initial postprocessing was performed using in-house software as implemented in MATLAB. Thirty-twochannel data were recombined in a weighted fashion, with coil weights and phases determined using the magnitude and phase, respectively, of the first time-domain point of the water-unsuppressed data. Next, the subspectra resulting from SPECIAL preinversion on/off scans were subtracted from each other. After subtraction, a strict procedure to remove motion corrupted scans was used. We identified such scans by calculating a deviation metric for each individual scan by subtracting the scan from the average of all scans and then computing the root-mean-square of all of the spectral points in the difference vector. Scans with deviation metrics that fell $>2.6$ SDs above the average were deemed to have been corrupted by motion and were removed and this procedure was repeated until no motion corrupted scans remained. Next, a frequency and phase drift correction was performed by least-squares fitting of each scan to the first scan in the series using frequency and phase as adjustment parameters. This procedure was performed in the time domain using only the first $40 \mathrm{~ms}$ of data. After frequency and phase alignment of the scans, signal averaging was performed, resulting in a fully processed short-TE spectrum. All MRS data were analyzed in LCModel (Provencher, 2001) using a simulated basis set that consisted of 22 individual metabolite signals. Line width (full-width half-maximum) was $<0.065 \mathrm{ppm}(\sim 8$ $\mathrm{Hz})$ for all motor $(0.028 \pm 0.002)$ and visual cortex $(0.032 \pm 0.001)$ data, there were no signal-to-noise ratio outliers (adjusted boxplot rule [Pernet et al., 2013] for motor [95 \pm 4 ] or visual cortex [111 \pm 3 ] data and
Cramér-Rao lower bound values were reliably $<20 \%$ for each metabolite and brain region $[7 \pm<01 \%]$ ). Raw GABA and glutamate values in each voxel were referenced to creatine to yield normalized values (these ratios are henceforth referred to as concentrations). T1-weighted anatomical scans were segmented into gray and white matter using FAST (FMRIB's automated segmentation tool; Smith, 2002). Metabolite concentrations were subsequently corrected for the percentage (p) of gray and white matter and CSF in each voxel as follows: normalized concentration $\times$ $(\mathrm{pGM}+\mathrm{pWM}) /(\mathrm{pGM}+\mathrm{pWM}+\mathrm{pCSF})$.

Statistical analyses. All data were analyzed using MATLAB. $Z$-transformed values for all data pairs were homoscedastic. Data were non-normally distributed, so Spearman and partial Spearman correlation coefficients were computed. Bivariate outliers were detected using an adjusted boxplot rule (Pernet et al., 2013) and removed in the computation of skipped correlations (Wilcox, 2004). There was a single bivariate outlier in all PSE $\times$ metabolite pairs except the PSE $\times$ motor cortex GABA pair, which had two bivariate outliers. The WF $\times$ visual cortex GABA pair had two 2 outliers, whereas the $M_{\mathrm{dev}} \times$ visual cortex GABA pair had a single outlier. We computed $95 \%$ confidence intervals (CIs) for correlation coefficients based on 10,000 samples with the nonparametric bias-corrected and accelerated percentile bootstrap method. We interpret conflicts between conventional $p$-values and bootstrap CIs as suggestive. For directional (one-tailed) tests of whether two correlations were different, we resampled both data pairs, recomputed the numerical difference of the correlations (10,000 samples), and then computed the CIs of this distribution.

\section{Results}

Within voxels, motor cortex GABA correlated with glutamate $\left(r_{\mathrm{s}}=.81, p<0.01\right.$; CIs: 0.70, 0.96), whereas the relationship between visual cortex GABA and glutamate was weakly suggestive $\left(r_{\mathrm{s}}=0.47, p=0.09\right.$; CIs: $\left.0.06,0.71\right)$. Across voxels, GABA concentrations were uncorrelated $\left(r_{\mathrm{s}}=-0.24, p=0.40\right.$; CIs: -0.72 , $0.66)$, as were glutamate concentrations $\left(r_{\mathrm{s}}=-0.13, p=0.65\right.$; CIs: $-0.48,0.62)$, which is consistent with previous research (Puts and Edden, 2012).

There was a tendency for participants to underestimate comparison intervals in the duration discrimination task by $\sim 30 \mathrm{~ms}$, reflecting a positive time-order error $\left(M_{\mathrm{PSE}} \pm \mathrm{SE}: 529 \pm 12 \mathrm{~ms}\right.$, one-sample $t=2.37, p<0.05, d=0.63$; Fig. $1 D)$. Our prediction that positive time-order error, reflecting a rightward horizontal shift of the psychometric function, would be associated with elevated GABA was supported by a positive correlation between visual cortex GABA concentrations and PSEs $\left(r_{\mathrm{s}}=.67, p<0.01\right.$; Fig. $3 B$ ). Bootstrap resampling revealed that this effect was internally replicable (Fig. $3 E$ ). In contrast, duration discrimination precision, as measured by WF, did not correlate with visual cortex GABA concentrations $\left(r_{\mathrm{s}}=0.12, p=0.70\right.$; CIs: $\left.-0.56,0.80\right)$. The correlation between visual cortex GABA and PSEs remained significant when female participants' menstrual phase (Epperson et al., 2002) was included as a covariate $\left(r_{\mathrm{ps}}=0.67, p=0.01\right.$; CIs: $0.28,0.90)$. Although MRS-derived estimates of occipital cortex GABA concentrations are insensitive to circadian changes in GABA levels (Evans et al., 2010), timing is known to vary as a function of time of day (Lustig and Meck, 2001). However, the relationship between visual cortex GABA and PSEs remained stable when controlling for the time at which the duration discrimination task was completed, the time of the MR scan, and the temporal discrepancy between these two times $\left(r_{\mathrm{ps}}>0.62, p<\right.$ 0.03 ), suggesting that this relationship is not artifactual of circadian influences on GABA levels or interval timing. We next undertook three sets of control analyses to examine the anatomical, neurochemical, and task specificity of this relationship.

Our first set of control analyses investigated the anatomical specificity of the relationship between visual cortex GABA con- 


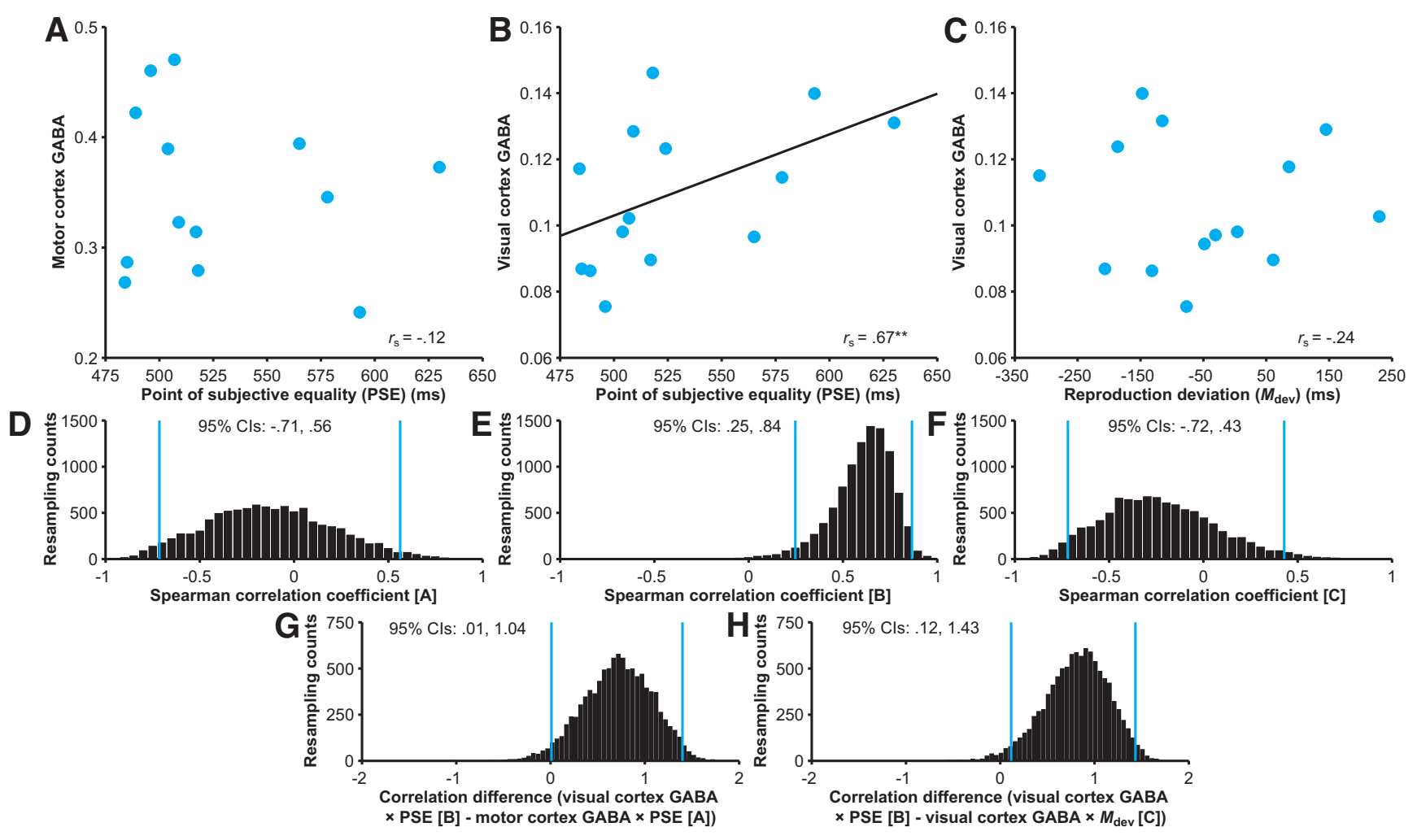

Figure 3. Relationships between GABA concentrations and task performance. $A$, Motor cortex GABA concentrations are unrelated to PSEs in the duration discrimination task. $B$, Visual cortex GABA concentrations correlate with PSEs. $\boldsymbol{C}$, Visual cortex GABA concentrations are unrelated to $M_{\mathrm{dev}} \mathrm{s}$ in the duration reproduction task. $\boldsymbol{D}-\boldsymbol{F}$, Bootstrap resampling data (blue lines indicate $95 \% \mathrm{Cls}$ ) for the correlations between motor cortex GABA concentrations and PSEs $(\boldsymbol{D})$, visual cortex GABA concentrations and PSEs $(\boldsymbol{E})$, and visual cortex GABA concentrations and $M_{\text {dev }} S(\boldsymbol{F})$. $\mathbf{G}-\boldsymbol{H}$, Bootstrap resampling data for the difference between $\boldsymbol{E}$ and $\boldsymbol{D}(\boldsymbol{G})$ and $\boldsymbol{E}$ and $\boldsymbol{F}(\boldsymbol{H}) .{ }^{* *} p<0.01$.

centrations and PSEs. Motor cortex GABA concentrations did not correlate with PSEs $\left(r_{\mathrm{s}}=-0.12, p=0.71\right.$; Fig. $\left.3 A, D\right)$. Moreover, a bootstrap resampling analysis showed that the correlation between visual cortex GABA concentrations and PSEs was significantly greater than that between motor cortex GABA concentrations and PSEs (resampling median difference: 0.75; Fig. 3G). In addition, visual cortex GABA concentrations still correlated with PSEs when motor cortex GABA concentrations were partialled out $\left(r_{\mathrm{ps}}=0.68, p=0.01\right.$; CIs: $\left.0.26,0.89\right)$.

Next, we investigated the neurochemical specificity of the relationship between visual cortex GABA concentrations and PSEs by examining the relationship between visual cortex glutamate concentrations and PSEs. Visual cortex glutamate concentrations did not correlate with PSEs $\left(r_{\mathrm{s}}=0.46, p=0.10\right.$; CIs: $\left.-0.16,0.81\right)$ and the relationship between PSEs and visual cortex GABA concentrations remained suggestive when visual cortex glutamate was partialled out $\left(r_{\mathrm{ps}}=0.57, p=0.040\right.$; CIs: $\left.-0.06,0.83\right)$, although the two correlations did not differ (resampling median difference: 0.19, -0.35 , $0.47)$. One explanation for the observed relationship between visual cortex GABA concentrations and perceived duration is that there is a disruption in the normal ratio of glutamate to GABA (i.e., the excitation/inhibition balance; Yizhar et al., 2011) such that underestimation is driven by an attenuated ratio. In preliminary support of this hypothesis, PSEs suggestively correlated with the glutamate/GABA ratio in visual cortex $\left(r_{\mathrm{s}}=-0.50, p=0.07\right.$; CIs: $\left.-0.66,-0.01\right)$, but were unrelated to the glutamate/GABA ratio in motor cortex $\left(r_{\mathrm{s}}=\right.$ $-0.21, p=0.47)$.

Our final set of analyses examined the task specificity of the relationship between visual cortex GABA concentrations and PSEs. Participants displayed a modest, albeit nonsignificant, tendency to overreproduce test intervals in the duration reproduction task $\left(M_{\mathrm{dev}}\right.$ $\pm \mathrm{SE}:-77 \pm 44 \mathrm{MS}$, one-sample $t=1.73, p=0.11, d=0.45) . M_{\mathrm{dev}} \mathrm{s}$ were unrelated to brain metabolite concentrations of visual cortex $\operatorname{GABA}\left(r_{\mathrm{s}}=-0.24, p=0.42\right.$; Fig. $\left.3 C, F\right)$. Moreover, the correlation between visual cortex GABA concentrations and PSEs was significantly greater than that between visual cortex GABA concentrations and $M_{\mathrm{dev}} \mathrm{s}$ (resampling median difference: 0.86; Fig. $3 H$ ) and remained significant when controlling for $M_{\mathrm{dev}} \mathrm{s}\left(r_{\mathrm{ps}}=0.62, p=0.024\right.$; CIs: $0.01,0.88)$. Reproduction performance may not have correlated with visual cortex GABA concentrations because of the inclusion of both subsecond and suprasecond intervals, which may be timed by different neural mechanisms (Lewis and Miall, 2003; Ivry and Schlerf, 2008; Buonomano et al., 2009; Spencer et al., 2009). To exclude this possibility, we recomputed the $M_{\mathrm{dev}}$ measure for 450 and $600 \mathrm{~ms}$ test intervals, which were in the temporal range of the comparison intervals in the duration discrimination task. Visual cortex GABA concentrations were unrelated to this measure ( $r=$ $-0.32, p=0.27$; CIs: $-0.66,0.20)$, suggesting that it does not mediate individual differences in duration reproduction.

To control for the possibility of false positives, a false discovery rate (Benjamini and Yekutieli, 2001) correction was applied to the set of $p$-values comprising the correlations between visual cortex GABA concentrations and PSEs and WFs and the series of control correlations; the relationship between visual cortex GABA concentrations and PSEs remained significant $(p<0.050)$.

\section{Discussion}

Our results demonstrate that the perceived duration of subsecond visual intervals is associated with resting state GABA concen- 
trations in visual cortex. GABA concentrations in primary visual cortex correlated positively with time-order error, accounting for $\sim 45 \%$ of the variance, indicating that elevated GABA is associated with a rightward horizontal shift in the psychometric function, reflecting relative underestimation of comparison intervals. Bootstrap resampling analyses also showed that this relationship is internally replicable. Further results point to the specificity of this relationship. Time-order error was unrelated to GABA concentrations in motor cortex and the relationship between time-order error and visual cortex GABA concentrations was independent of motor cortex GABA concentrations, indicating that the observed effect is specific to visual cortex. Time-order error was also unrelated to glutamate concentrations in visual cortex, thereby specifically implicating inhibitory activity in the perceived duration of visual intervals. Finally, GABA concentrations were unrelated to precision of duration discrimination and to duration reproduction, which suggests that GABA is specifically associated with the perceived duration of visual intervals. Cumulatively, these results demonstrate anatomical, chemical, and task specificity and suggest a role for visual cortex GABA concentrations in the perceived duration of subsecond visual intervals.

The current results bridge findings from disparate research areas and are consistent with the hypothesis that resting-state GABA concentrations contribute to interindividual variability in time-order error in duration discrimination. Our results complement electrophysiological research in macaques showing that perceived duration is a consequence of the magnitude of the neuronal response to visual intervals (Sadeghi et al., 2011; Mayo and Sommer, 2013; see also Eagleman and Pariyadath, 2009). The present findings further suggest a link between electrophysiological results and pharmacological and neuroimaging studies implicating GABA in visual processing (Edden et al., 2009; van Loon et al., 2012). Elevated GABA may attenuate visual processing through inhibition of sensory-specific excitatory activity (Watson et al., 2009; Muthukumaraswamy et al., 2012). Our results suggest that this has the consequence of contracting the relative duration of comparison intervals, resulting in a rightward horizontal shift of psychometric functions (positive time-order error). Research showing that a $\mathrm{GABA}_{\mathrm{A}}$ agonist impaired interval discrimination of auditory intervals (Rammsayer, 1992; Rammsayer, 1999) suggests that this relationship may extend beyond the visual domain. Insofar as GABA contributes to network dynamics by helping to shape network oscillatory patterns (Möhler, 2007; Buzsáki and Wang, 2012), the present results are also consistent with network models proposing that the brain may time an interval on the basis of state-dependent network dynamics (e.g., short-term synaptic plasticity) during the interval (Buonomano and Merzenich, 1995; Karmarkar and Buonomano, 2007). However, there is evidence that such models are restricted to intervals up to $300 \mathrm{~ms}$ (Spencer et al., 2009) and thus may not be applicable to the interval range of the present study. It may be that time-order error is determined by constraints of the local ratio of glutamate to GABA in visual cortex (excitation-inhibition balance; Yizhar et al., 2011) on sensory-specific neuronal activity, rather than variability in GABA concentrations, but we found only suggestive evidence for this possibility.

If elevated GABA concentrations produce contraction of timed intervals, one might expect that they would contract both standard and comparison intervals and thus that there would be no relationship between GABA concentrations and time-order error. However, the standard intervals were serially sampled, thereby ensuring a stable representation, whereas comparison intervals were only infrequently sampled, so their representation was more susceptible to transient constraints on visual processing, such as GABAergic inhibition. Furthermore, comparison intervals are weighted more strongly than standard intervals in interval timing judgments (Dyjas and Ulrich, 2013) and such judgments tend to be made in reference to an internal reference (the average of comparison durations) rather than the standard interval (Allan, 1979; Shi et al., 2013). Accordingly, any contraction of standard intervals would not be as pronounced as that of comparison intervals nor would it be expected to substantially influence interval judgments.

An alternative interpretation of our results is that visual cortex GABA concentrations constrain the neuronal response to the duration of visual intervals and thus represents inhibition of the encoding or maintenance of temporal information rather than inhibition of neuronal responses related to visual processing. For example, a recent study (Salvioni et al., 2013) found that rTMS applied to V1 and V5/MT attenuated precision, as measured by the $\mathrm{WF}$, in a duration discrimination task, but not low-level visual processing. Although this represents a plausible interpretation that is worthy of further research, a number of features of the present study more strongly favor a sensory processing interpretation. First, we observed our effect in the PSE, which represents a measure of perceptual bias toward relative contraction or dilation of the comparison interval, not precision. Second, Salvioni et al. (2013) used an empty interval task similar to the reproduction task we used as a control, which is less likely to tax visual processing (see also Gorea, 2011). Finally, multiple studies have supported a link between variability in visual cortex GABA levels and individual differences in visual processing (Edden et al., 2009; Yoon et al., 2010; van Loon et al., 2012), rendering a role for GABA in coding for visual stimuli more likely than a role coding for visual intervals per se. Further research is required to more clearly discriminate between these competing interpretations.

Further questions remain regarding the temporal locus of GABA's influence on interval timing. A recent study found that a $\mathrm{GABA}_{\mathrm{A}}$ receptor agonist did not affect early visual processing $(<120 \mathrm{~ms})$, but deleteriously affected later processing ( $>150 \mathrm{~ms}$; van Loon et al., 2012). Other research found that a $\mathrm{GABA}_{\mathrm{A}}$ agonist impaired auditory interval discrimination with $1000 \mathrm{~ms}$, but not with $100 \mathrm{~ms}$, intervals (Rammsayer, 1992; Rammsayer, 1999). These results and the likelihood that MRS is measuring (extrasynaptic) GABA tone (Stagg et al., 2011a; Stagg et al., 2011c), which may lead to slower effects on cortical processing, suggest that elevated GABA will be associated with time-order error only for intervals $>150 \mathrm{~ms}$. The upper temporal limit of GABA's influence on interval timing is less clear. The neural mechanisms underlying the perception of subsecond intervals differ from those that subserve suprasecond intervals (Lewis and Miall, 2003; Gooch et al., 2011), so it is plausible that the relationship between resting state GABA concentrations and time-order error is restricted to short intervals (see also Gorea, 2011). Because the principal aim of this study was to examine the relationship between GABA and time-order error for subsecond intervals, following on from previous macaque electrophysiology research (Mayo and Sommer, 2013), we did not measure suprasecond interval discrimination. The inclusion of suprasecond intervals in future research may help to dissociate additive effects, which are attentional effects pertaining to switch closure latency in pacemaker-accumulator models of interval timing and are independent of duration, and multiplicative effects, which pertain to arousal-specific changes in pacemaker speed and should only affect long durations (Maricq et al., 1981; Penney et al., 2000). It 
is unlikely that the observed relationship represents an arousal effect because of the latency of the intervals, but also because of the topography of the effect. Contrasting interval and color discrimination could help to determine roles for attention and working memory in the observed relationship (Coull et al., 2004). However, we recently found that variability in visual cortex GABA concentrations was unrelated to individual differences in color working memory (D.B. Terhune, L. Murray, and R. Cohen Kadosh, unpublished observations). This suggests that the observed effect is driven by the relationship between GABA concentrations and visual perception, which is consistent with research suggesting that the time-order error is perceptual (Dyjas and Ulrich, 2013).

Considerable attention has been devoted to whether time perception is subserved by dedicated modality-independent timing mechanisms such as a pacemaker-accumulator internal clock system or intrinsic mechanisms such as local sensory-specific neuronal activity (for review, see Ivry and Schlerf, 2008). One way of reconciling these positions is the hypothesis that intrinsic mechanisms process subsecond intervals, whereas dedicated timing circuits process suprasecond intervals (Ivry and Schlerf, 2008; Coull et al., 2011). Alternatively, it may be that time perception is enabled by a core cortical-thalamic basal ganglia circuit that receives signals from local sensory-specific areas (Merchant et al., 2013). Therefore, elevated endogenous GABA may alter the timing signal produced by the local neuronal response to a stimulus before it is processed upstream in a core timing circuit, thereby affecting the pacemaker or accumulator. Recent fMRI evidence implicating putamen in the timing of subsecond visual intervals (Coull et al., 2012) is consistent with this idea. Regardless of whether they are more closely aligned with intrinsic mechanisms or a hybrid model, our results suggest that endogenous GABA concentrations represent a local source of the interindividual heterogeneity often observed in subsecond visual interval timing (Wiener et al., 2013). Further research on the role of GABA in visual processing is likely to expand our understanding of the neural basis of time perception, including timing deficits in clinical populations (Allman and Meck, 2012) and the possibility of modulating GABA noninvasively (Stagg et al., 2011b) to improve atypical time perception.

\section{References}

Allan LG (1979) The perception of time. Attention Perception and Psychophysics 26:340-354. CrossRef

Allman MJ, Meck WH (2012) Pathophysiological distortions in time perception and timed performance. Brain 135:656-677. CrossRef Medline

Benjamini Y, Yekutieli D (2001) The control of the false discovery rate in multiple testing under dependency. Annals of Statistics 29:1165-1188. CrossRef

Bueti D (2011) The sensory representation of time. Front Integr Neurosci 5:34. CrossRef Medline

Buhusi CV, Meck WH (2009) Relative time sharing: new findings and an extension of the resource allocation model of temporal processing. Philos Trans R Soc Lond B Biol Sci 364:1875-1885. CrossRef Medline

Buonomano DV, Merzenich MM (1995) Temporal information transformed into a spatial code by a neural network with realistic properties. Science 267:1028-1030. CrossRef Medline

Buonomano DV, Bramen J, Khodadadifar M (2009) Influence of the interstimulus interval on temporal processing and learning: Testing the state-dependent network model. Philos Trans R Soc Lond B Biol Sci 364:1865-1873. CrossRef Medline

Buzsáki G, Wang XJ (2012) Mechanisms of gamma oscillations. Annu Rev Neurosci 35:203-225. CrossRef Medline

Chapman LJ, Chapman JP (1987) The measurement of handedness. Brain Cogn 6:175-183. CrossRef Medline

Coull JT, Vidal F, Nazarian B, Macar F (2004) Functional anatomy of the attentional modulation of time estimation. Science 303:1506-1508. CrossRef Medline

Coull JT, Cheng RK, Meck WH (2011) Neuroanatomical and neurochemical substrates of timing. Neuropsychopharmacology 36:3-25. CrossRef Medline

Coull JT, Hwang HJ, Leyton M, Dagher A (2012) Dopamine precursor depletion impairs timing in healthy volunteers by attenuating activity in putamen and supplementary motor area. J Neurosci 32:16704-16715. CrossRef Medline

Dyjas O, Ulrich R (2013) Effects of stimulus order on discrimination processes in comparative and equality judgements: data and models. Q J Exp Physiol (Hove), in press. Medline

Eagleman DM, Pariyadath V (2009) Is subjective duration a signature of coding efficiency? Philos Trans R Soc Lond B Biol Sci 364:1841-1851. CrossRef Medline

Edden RA, Muthukumaraswamy SD, Freeman TC, Singh KD (2009) Orientation discrimination performance is predicted by GABA concentration and gamma oscillation frequency in human primary visual cortex. J Neurosci 29:15721-15726. CrossRef Medline

Epperson CN, Haga K, Mason GF, Sellers E, Gueorguieva R, Zhang W, Weiss E, Rothman DL, Krystal JH (2002) Cortical gamma-aminobutyric acid levels across the menstrual cycle in healthy women and those with premenstrual dysphoric disorder: a proton magnetic resonance spectroscopy study. Arch Gen Psychiatry 59:851-858. CrossRef Medline

Evans CJ, McGonigle DJ, Edden RA (2010) Diurnal stability of gammaaminobutyric acid concentration in visual and sensorimotor cortex. J Magn Reson Imaging 31:204-209. CrossRef Medline

Giersch A, Herzog MH (2004) Lorazepam strongly prolongs visual information processing. Neuropsychopharmacology 29:1386-1394. CrossRef Medline

Gooch CM, Wiener M, Hamilton AC, Coslett HB (2011) Temporal discrimination of sub- and suprasecond time intervals: a voxel-based lesion mapping analysis. Front Integr Neurosci 5:59. Medline

Gorea A (2011) Ticks per thought or thoughts per tick? A selective review of time perception with hints on future research. J Physiol Paris 105:153163. CrossRef Medline

Grondin S (2010) Timing and time perception: A review of recent behavioral and neuroscience findings and theoretical directions. Atten Percept Psychophys 72:561-582. CrossRef Medline

Hellström A (1985) The time-order error and its relatives: mirrors of cognitive processes in comparing. Psychological Bulletin 97:35-61. CrossRef

Hellström A (2003) Comparison is not just subtraction: Effects of time- and space-order on subjective stimulus difference. Percept Psychophys 65: 1161-1177. CrossRef Medline

Ivry RB, Schlerf JE (2008) Dedicated and intrinsic models of time perception. Trends Cogn Sci 12:273-280. CrossRef Medline

Karmarkar UR, Buonomano DV (2007) Timing in the absence of clocks: Encoding time in neural network states. Neuron 53:427-438. CrossRef Medline

Kingdom FAA, Prins N (2010) Psychophysics: a practical introduction. London: Elsevier.

Lewis PA, Miall RC (2003) Distinct systems for automatic and cognitively controlled time measurement: evidence from neuroimaging. Curr Opin Neurobiol 13:250-255. CrossRef Medline

Lustig C, Meck WH (2001) Paying attention to time as one gets older. Psychol Sci 12:478-484. CrossRef Medline

Maricq AV, Roberts S, Church RM (1981) Methamphetamine and time estimation. J Exp Psychol Animal Behav Proc 7:18-30. CrossRef

Mauk MD, Buonomano DV (2004) The neural basis of temporal processing. Annu Rev Neurosci 27:307-340. CrossRef Medline

Mayo JP, Sommer MA (2013) Neuronal correlates of visual time perception at brief timescales. Proc Natl Acad Sci U S A 110:1506-1511. CrossRef Medline

Mekle R, Mlynárik V, Gambarota G, Hergt M, Krueger G, Gruetter R (2009) MR spectroscopy of the human brain with enhanced singla intensity at ultrashort echo times on a clinical platform at 3T and 7T. Magn Reson Med 61:1279-1285. CrossRef Medline

Merchant H, Harrington DL, Meck WH (2013) Neural basis of the perception and estimation of time. Annu Rev Neurosci 36:313-336. CrossRef Medline

Möhler H (2007) Molecular regulation of cognitive functions and develop- 
mental plasticity: impact of $\mathrm{GABA}_{\mathrm{A}}$ receptors. J Neurochem 102:1-12. CrossRef Medline

Muthukumaraswamy SD, Evans CJ, Edden RA, Wise RG, Singh KD (2012) Individual variability in the shape and amplitude of the BOLD-HRF correlates with endogenous GABAergic inhibition. Hum Brain Mapp 33: 455-465. CrossRef Medline

Penney TB, Gibbon J, Meck WH (2000) Differential effects of auditory and visual signals on clock speed and temporal memory. J Exp Psychol Hum Percept Perform 26:1770-1787. CrossRef Medline

Pernet CR, Wilcox R, Rousselet GA (2013) Robust correlation analyses: false positive and power validation using a new open source Matlab toolbox. Front Psychol 3:606. CrossRef Medline

Prins N, Kingdom FA (2009) Palamedes: Matlab routines for analyzing psychophysical data. Available from: http://www.palamedestoolbox.org. Accessed September 17, 2013.

Provencher SW (2001) Automatic quantitation of localized in vivo 1H spectra with LCModel. NMR Biomed 14:260-264. CrossRef Medline

Puts NA, Edden RA (2012) In vivo magnetic resonance spectroscopy of GABA: A methodological review. Prog Nucl Magn Reson Spectrosc 60: 29-41. CrossRef Medline

Rammsayer T (1992) Effects of benzodiazepine-induced sedation on temporal processing. Human Psychopharmacology 7:311-318. CrossRef

Rammsayer TH (1999) Neuropharmacological evidence for different timing mechanisms in humans. Q J Exp Psychol B 52:273-286. Medline

Sadeghi NG, Pariyadath V, Apte S, Eagleman DM, Cook EP (2011) Neural correlates of subsecond time distortion in the middle temporal area of visual cortex. J Cogn Neurosci 23:3829-3840. CrossRef Medline

Salvioni P, Murray MM, Kalmbach L, Bueti D (2013) How the visual brain encodes and keeps track of time. J Neurosci 33:12423-12429. CrossRef Medline

Shi Z, Church RM, Meck WH (2013) Bayesian optimization of time perception. Trends Cogn Sci 17:556-564. CrossRef Medline

Smith SM (2002) Fast robust automated brain extraction. Hum Brain Mapp 17:143-155. CrossRef Medline

Spencer RM, Karmarkar U, Ivry RB (2009) Evaluating dedicated and intrinsic models of temporal encoding by varying context. Philos Trans R Soc Lond B Biol Sci 364:1853-1863. CrossRef Medline

Stagg CJ, Bachtiar V, Johansen-Berg H (2011a) What are we measuring with
GABA magnetic resonance spectroscopy? Commun Integr Biol 4:573575. CrossRef Medline

Stagg CJ, Bachtiar V, Johansen-Berg H (2011b) The role of GABA in human motor learning. Curr Biol 21:480-484. CrossRef Medline

Stagg CJ, Bestmann S, Constantinescu AO, Moreno LM, Allman C, Mekle R, Woolrich M, Near J, Johansen-Berg H, Rothwell JC (2011c) Relationship between physiological measures of excitability and levels of glutamate and GABA in the human motor cortex. J Physiol 589:5845-5855. CrossRef Medline

Sysoeva OV, Tonevitsky AG, Wackermann J (2010) Genetic determinants of time perception mediated by the serotonergic system. PLoS One 5:pii: e12650. CrossRef Medline

Terao M, Watanabe J, Yagi A, Nishida S (2008) Reduction of stimulus visibility compresses apparent time intervals. Nat Neurosci 11:541-542. CrossRef Medline

Tkác I, Andersen P, Adriany G, Merkle H, Ugurbil K, Gruetter R (2001) In vivo $1 \mathrm{H}$ NMR spectroscopy of the human brain at 7 T. Magn Reson Med 46:451-456. CrossRef Medline

van Loon AM, Scholte HS, van Gaal S, van der Hoort BJ, Lamme VA (2012) $\mathrm{GABA}_{\mathrm{A}}$ agonist reduces visual awareness: a masking EEG experiment. J Cogn Neurosci 24:965-974. CrossRef Medline

Watson TD, Petrakis IL, Edgecombe J, Perrino A, Krystal JH, Mathalon DH (2009) Modulation of the cortical processing of novel and target stimuli by drugs affecting glutamate and GABA neurotransmission. Int J Neuropsychopharmacol 12:357-370. CrossRef Medline

Wiener M, Lee YS, Lohoff FW, Coslett HB (2013) Individual differences in the morphometry and activation of time perception networks are influenced by dopamine genotype. Neuroimage 89:10-22. CrossRef Medline

Wilcox RR (2004) Inferences based on a skipped correlation coefficient. Journal of Applied Statistics 31:131-143. CrossRef

Yizhar O, Fenno LE, Prigge M, Schneider F, Davidson TJ, O'Shea DJ, Sohal VS, Goshen I, Finkelstein J, Paz JT, Stehfest K, Fudim R, Ramakrishnan C, Huguenard JR, Hegemann P, Deisseroth K (2011) Neocortical excitation/inhibition balance in information processing and social dysfunction. Nature 477:171-178. CrossRef Medline

Yoon JH, Maddock RJ, Rokem A, Silver MA, Minzenberg MJ, Ragland JD, Carter CS (2010) GABA concentration is reduced in visual cortex in schizophrenia and correlates with orientation-specific surround suppression. J Neurosci 30:3777-3781. CrossRef Medline 